\title{
Pengaruh Lagu Wayang Sukuraga Terhadap Keterampılan Menulis Karangan Argumentasi Di Kelas Tinggi Sekolah Dasar
}

\author{
Intan Agustian $1 *$, Dyah Lyesmaya ${ }^{2}$, Irna Khaleda ${ }^{3}$ \\ ${ }^{1}$ Universitas Muhammadiyah Sukabumi, Indonesia \\ 2Universitas Muhammadiyah Sukabumi, Indonesia \\ ${ }^{3}$ Universitas Muhammadiyah Sukabumi, Indonesia \\ *Corresponding author: intan@ummi.ac.id
}

\begin{abstract}
This research is motivated by the low level of students' argumentative essay writing skills which are influenced by the media used in learning that is less than optimal. Educators only use learning book media without any use of media that can motivate and attract. One of the media that can influence the improvement of argumentative essay writing skills is through song media. This study aims to determine the effect of the media song wayang sukuraga on learning outcomes in writing argumentative essays in high school grades. This research method is quasi-experimental with two class groups, namely experimental and control. The research population is the fifth grade students of SDN Baros Kencana CBM. The research sample was selected based on a saturated sample with a total of 40 students from both classes. The data collection technique is the test instrument. The results of the posttest scores of the experimental class were higher than the control class. It can be seen that based on the results of hypothesis testing using the Independent Sample T-Test test, the sig value is obtained. $=0.003$ because the value of sig. $<0.05$ then $H_{0}$ is rejected and $H_{I}$ is accepted, meaning that there is a significant difference between the experimental class and the control class. The conclusion is that the wayang sukuraga song affects the students' argumentative writing skills at V SDN Baros Kencana CBM in 2020/2021.
\end{abstract}

Keywords: argumentation writing skills; sukuraga puppet song

\section{ABSTRAK}

Penelitian ini di latarbelakangi rendahnya keterampilan menulis karangan argumentasi siswa yang dipengaruhi oleh media yang digunakan pembelajaran kurang maksimal. Pendidik hanya menggunakan media buku pembelajaran tanpa ada penggunaan media yang dapat memotivasi dan menarik. Salah satu media yang dapat mempengaruhi meningkatnya keterampilan menulis karangan argumentasi adalah melalui media lagu. Penelitian ini bertujuan untuk mengetahui pengaruh media lagu wayang sukuraga terhadap hasil belajar menulis karangan argumentasi di kelas tinggi sekolah dasar. Metode penelitian ini adalah quasi eksperimen dengan dua kelompok kelas, yaitu eksperimen dan kontrol. Populasi penelitian adalah siswa kelas V SDN Baros Kencana CBM. Sampel penelitian dipilih berdasarkan sampel jenuh dengan jumah 40 siswa dari kedua kelas. Teknik pengumpulan data yaitu instrumen tes. Hasil perolehan nilai posttest kelas eksperimen lebih tinggi dibandingkan dengan kelas kontrol. Hal tersebut dilihat berdasarkan hasil uji hipotesis menggunakan uji Independent Sampel T-Test diperoleh nilai sig. $=0,003$ karena nilai sig. $<0,05$ maka $\mathrm{H}_{0}$ ditolak dan $\mathrm{H}_{1}$ diterima, artinya terdapat perbedaan yang signifikan antara kelas eksperimen dan kelas kontrol. Kesimpulannya adalah lagu wayang sukuraga berpengaruh terhadap keterampilan menulis karangan argumentasi siswa di V SDN Baros Kencana CBM tahun 2020/2021.

Kata Kunci: lagu wayang sukuraga; keterampilan menulis karangan argumentasi

\section{Pendahuluan}

Pendidikan dasar merupakan jenjang yang sangat penting dalam mempelajari bahasa Indonesia. Pada tahap tersebut peserta didik dapat mengembangkan aspek sosial, intelektual, dan emosional yang dapat dijadikan pondasi keberhasilan pendidikan jenjang selanjutnya. Hal tersebut mengacu pada keterampilan berbahasa menurut (Azhari et al., : 2019) yang saling berkaitan satu sama diantaranya menyimak, berbicara, membaca dan menulis. Menulis merupakan salah satu aspek berbahasa dengan komunikasi tidak langsung. Menurut Siddik (2016: 3) menulis adalah pengungkapan ide, gagasan atau perasaan seseorang yang dituangkan melalui lambang grafik yang disebut dengan tulisan. Febriyanto dan Yanto (2019) mengemukakan bahwa keterampilan menulis merupakan sebuah proses sehingga untuk 
memiliki keterampilan menulis yang baik dilakukan dengan berlatih menulis secara berkesinambungan. Kemampuan seseorang dalam menulis ditentukan oleh adanya kemauan dan sering berlatih dalam membuat suatu karangan. Karangan argumentasi merupakan salah satu pembelajaran yang sangat penting dicapai oleh siswa, karena terdapat dalam pembelajaran kurikulum 2013 di sekolah dasar agar siswa terampil dalam menyampaikan gagasannya dalam bentuk tertulis. Karangan argumentasi merupakan karangan yang disertai pendapat serta bukti logis agar dapat mempengaruhi pembacanya (Siddik, 2016: 25-36). Pada kenyataannya masih banyak siswa yang merasa kesulitan dalam memulai sebuah tulisan argumentasi. Hal tersebut terjadi karena rendahnya penguasaan kosakata yaitu dalam diksi, tanda baca, penyusunan kalimat dan paragraf, kesulitan menemukan ide untuk menulis karangan argumentasi dan keterbatasan media yang efektif dalam pembelajaran yang kurang memotivasi dan membangkitkan minat siswa menjadi beberapa faktor rendahnya kemampuan siswa dalam menulis karangan argumentasi (Juwita \& Nasution, 2018: 2). Salah satu cara untuk meningkatkan keterampilan menulis karangan argumentasi siswa yaitu guru menggunakan teknik dan media yang dapat memunculkan ide serta pendapat siswa.

Penggunaan media pembelajaran dalam kegiatan belajar mengajar dapat lebih menarik atensi siswa sehingga lebih memotivasi siswa untuk belajar. Media merupakan pelantara yang dapat membantu ketidakjelasan pembelajaran yang disampaikan. Salah satu media yang diasumsikan dapat meningkatkan keterampilan menulis karangan argumentasi ialah melalui lagu. Menurut Sheppard dalam (Maulidiyah \& Yermiandhoko, 2019: 246) penerimaan informasi melalui bentuk tulisan dinilai lebih sulit, namun jika suatu tulisan tersebut disajikan melalui melodi dan musik dalam suatu lagu, maka informasi yang ada dalam lagu tersebut akan lebih mudah dipahami dan diingat. Media lagu dalam proses pembelajaran dapat dijadikan alternatif untuk meningkatkan kemampuan menulis karangan argumentasi, karena menurut penelitian Juwita \& Nasution (2018: 10) media lagu berpengaruh terhadap terciptanya suasana pembelajaran yang nyaman sehingga dapat memberikan sugesti dalam mengembangkan kreatifitas dan imajinasi dalam berkarya. Adapun penelitian yang dilakukan oleh Tristanto \& Sutikno (2018: 78) bahwa pengaruh media lagu terhadap hasil belajar siswa mencapai ketuntasan belajar klasikal, hasil belajar menggunakan media lagu lebih efektif dalam pembelajaran. Selanjutnya, penelitian dari Anggraeni. (2016: 57) yang bertujuan meningkatkan hasil pembelajaran menulis puisi siswa menggunakan media lagu anak. Hasil dari penelitian ini menunjukkan adanya perubahan positif yaitu peningkatan kemampuan siswa kelas $\mathrm{V}$ dalam menulis puisi serta dapat memotivasi siswa dalam mengikuti pembelajaran.

Perbedaan media yang digunakan penulis dengan penelitian lain yaitu penulis memilih salah satu lagu dari kesenian wayang sukuraga yaitu tentang mata dan telinga sebagai media yang digunakan untuk membantu siswa dalam keterampilan menulis karangan argumentasi. Berbeda dengan wayang pada umumnya, yang menceritakan tentang kisah Ramayana dan Mahabrata. Wayang sukuraga ini merupakan wayang kontemporer khas dari Sukabumi, yang bentuknya unik yakni setiap tokohnya berbentuk bagian-bagian dari anggota tubuh manusia. Wayang sukuraga memiliki cerita dan penokohan yang diadaptasi dari kehidupan masyarakat sehari-hari. Menurut Effendi (Kampung Sukuraga, 2020) lirik lagu mata dan telinga wayang sukuraga berisi penyampaian nasihat mengenai apa yang seharusnya dilakukan oleh manusia sesuai dengan apa yang diperintahkan dan apa yang dilarang oleh sang pencipta untuk lebih mengenal diri. Pesan yang disampaikan kepada siswa 
diinterpretasikan lewat anggota tubuh mereka sendiri. Sehingga, penerapan lagu wayang sukuraga dalam kegiatan pembelajaran dapat lebih menarik perhatian dan menstimulus siswa dalam menulis karangan argumentasi. Tujuan dari dilaksanakannya penelitian ini adalah untuk mengetahui apakah lagu wayang sukuraga berpengaruh terhadap keterampilan menulis karangan argumentasi di kelas tinggi sekolah dasar.

\section{Metode Penelitian}

Penelitian ini menggunakan Quasi Experimental Design. Desain ini mempunyai kelompok kontrol namun tidak dapat berfungsi sepentuhnya dalam mengontrol variabelvarabel luar (Sugiyono, 2018:114). Alasan peneliti menggunakan Quasi Experimental Design karena situasi kelas yang digunakan sebagai tempat perlakuan tidak memungkinkan peneliti mengontrol variabel secara ketat, dengan demikian peneliti hanya mengontrol keadaan sesuai dengan kondisi yang ada. Penelitian jenis ini menggunakan dua kelas yaitu kelas eksperimen dan kelas kontrol. Kelas eksperimen merupakan kelas yang diberikan perlakuan kepada siswa dengan menerapkan lagu wayang sukuraga saat melaksanakan proses pembelajaran. Adapun kelas kontrol merupakan siswa yang melaksanakan proses pembelajaran tanpa adanya perlakuan. Lagu wayang sukuraga ini akan berpengaruh atau tidaknya terhadap keterampilan menulis karangan argumentasi siswa di kelas tinggi sekolah dasar.

Model desain penelitian yang digunakan adalah Nonequivalent Control Group Design. Menurut Sugiyono (2018: 116) Nonequivalent Control Group Design merupakan model desain penelitian eksperimen yang tidak melalui proses pemilihan secara random dalam menentukan antara kelas eksperimen dan kelas kontrol. Dalam mengetahui kemampuan awal siswa, kedua kelas diberi pretest yaitu sebelum diberikan perlakuan Kemudian memilih kelas eksperimen untuk dapat diterapkannya perlakuan dan kelas kontrol penelitian yang tidak diberikan perlakuan. Peneliti kemudian memberikan posttest setelah kegiatan tersebut berlangsung. Hal ini bertujuan untuk mengetahui apakah ada perbedaan yang signifikan sebelum dan sesudah diterapkannya perlakuan dalam penelitian.

\begin{tabular}{|cccc|}
\hline $\mathrm{E}$ & $\mathrm{O}_{1}$ & $\mathrm{X}$ & $\mathrm{O}_{2}$ \\
\hline $\mathrm{K}$ & $\mathrm{O}_{3}$ & $\mathrm{O}_{4}$ \\
\hline
\end{tabular}

\section{Gambar 1. Nonequivalent Control Group Design}

Keterangan:

$\mathrm{E}=$ Kelas eksperimen

$\mathrm{K}=$ Kelas kontrol

$\mathrm{O}_{1}=$ Pre-test kelas eksperimen

$\mathrm{O}_{3}=$ Pre-test kelas kontrol

$\mathrm{O}_{2}=$ Post-test kelas eksperimen

$\mathrm{O}_{4}=$ Post-test kelas kontrol

$\mathrm{X}=$ Treatment yang diberikan pada kelas eksperimen

Penelitian ini akan dilaksanakan pada semester genap yaitu tahun ajaran 2020/2021. Teknik sampel dalam penelitian ini adalah teknik sampling jenuh. Subjek penelitian ini adalah kelas V SDN Baros Kencana CBM yaitu kelas VB dan VD. Secara garis besar, penelitian ini 
ingin mengetahui pengaruh lagu wayang sukuraga terhadap keterampilan menulis karangan argumentasi di kelas tinggi sekolah dasar. Instrumen yang digunakan dalam penelitian ini adalah instrumen tes berbentuk esai. Untuk pelaksanaan penelitian di kelas eksperimen yaitu diberikan tindakan dengan menerapkan lagu wayang sukuraga yang berjudul mata dan telinga, sedangkan di kelas kontrol tidak diberi perlakuan. Data yang sudah terkumpul selanjutnya dianalisis menggunakan uji normalitas, homogenitas, uji $t$ dua sampel berpasangan dan uji hipotesis yang bertujuan untuk mengetahui apakah ada perbedaan antara kelas eksperimen dan kelas kontrol.

\section{Hasil dan Pembahasan}

Data yang diperoleh dalam penelitian ini melibatkan dua kelas yaitu kelas eksperimen dengan diberikan perlakuan menerapkan lagu wayang sukuraga dalam pembelajaran dan kelas kontrol yang tidak diberikan perlakuan yaitu tanpa menerapkan lagu wayang sukuraga dalam pembelajaran. Untuk mengetahui pengetahuan awal siswa peneliti memberikan pretest dari kelas eksperimen dan kelas kontrol. Setelah dilaksanakannya penelitian tersebut, kelas eksperimen dan kelas kontrol diberikan posttest untuk mengetahui kemampuan akhir siswa. Berdasarkan hasil analisis nilai pretest rata-rata nilai yang diperoleh dari kemampuan awal pada kelas eksperimen yaitu 53,25 dengan jumlah siswa sebanyak 20 orang, sedangkan hasil nilai rata-rata kemampuan yang diperoleh kelas kontrol adalah 61,15 dengan jumlah siswa sebanyak 20 orang. Perolehan nilai paling tinggi pada kelas ekperimen yaitu 71 dan nilai paling rendahnya yaitu 35 . Sedangkan, pada kelas kontrol nilai tertingginya yaitu 80 dan paling rendah 45. Simpangan baku pada kelas eksperimen yaitu 10,477 dan kelas kontrol 10,241. Varians kelas eksperimen sebesar 109,776 dan kelas kontrol sebesar 104,871. Hasil analisis pengujian pretest dari uji $\mathrm{T}$ dua sampel independen diperoleh nilai sig. $=0,021$ karena nilainya sig. $<0,05$. Maka $\mathrm{H}_{0}$ diterima dan $\mathrm{H}_{1}$ ditolak. Sehingga dapat disimpulkan bahwa kelas eksperimen dan kelas kontrol mempunyai kemampuan awal yang sama.

Pengaruh Lagu Wayang Sukuraga terhadap Keterampilan Menulis Karangan Argumentasi Siswa

Penggunaan lagu wayang sukuraga yang telah digunakan dalam pembelajaran, dapat membantu siswa mempermudah menulis karangan argumentasi hal tersebut dapat dililhat dari perolehan hasil yang lebih baik diperoleh dari kelas eksperimen yaitu kelas yang menerapkan lagu wayang sukuraga dalam proses pembelajaran menulis karangan argumentasi. Kelas ekperimen memperoleh nilai rata-rata posttest sebesar 72,40 sedangkan kelas kontrol memperoleh nilai rata-rata sebesar 63,65. Berikut perbedaan hasil belajar antara kelas eksperimen dan kelas kontrol:

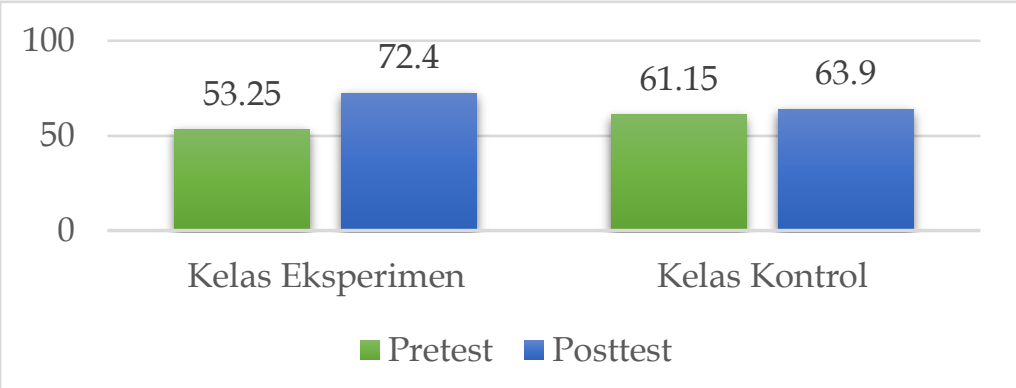

Gambar 1. Perbedaan Hasil Rata-Rata Nilai Pretest dan Posttest Kelas Eksperimen dan Kelas

Kontrol 
Perbedaan hasil pretest dan posttest dari kelas eksperimen dan kelas kontrol dilihat dari perolehan nilai rata-rata setelah diberikan perlakuan. Pada kelas eksperimen perolehan ratarata nilai pretest sebesar 53,25 dan posttest sebesar 72,4. Sedangkan perolehan rata-rata nilai pretest di kelas kontrol yaitu sebesar 61, 5 dan posttest sebesar 63,9. Dari hasil pengujian dapat disimpulkan bahwa pembelajaran dengan menggunakan lagu wayang sukuraga memberikan pengaruh terhadap keterampilan menulis karangan argumentasi siswa.

Hasil analisis data perolehan nilai pretest dan posttest kelas kontrol menggunakan uji Paired-Samples T Test memperoleh nilai sig. = 0,419 karena nilai sig. > 0,05 maka $\mathrm{H}_{0}$ diterima dan $\mathrm{H}_{1}$ ditolak. Dari hasil perolehan nilai tersebut dapat disimpulkan bahwa tidak terdapat perbedaan yang signifikan antara hasil pretest dan posttest kelas kontrol. Adapun, hasil pengujian uji Paired-Samples T Test kelas eksperımen memperoleh nilai sig (2-tailed) 0,000 karena nilai sig. $<0,05$ maka $\mathrm{H}_{0}$ ditolak dan $\mathrm{H}_{1}$ di terima. Sehingga dapat disimpulkan bahwa terdapat perbedaan yang signifikan antara hasil pretest dan posttest pada kelas eksperimen.

Hasil uji hipotesis menggunakan Independent Sample T-Test dengan taraf signifikansi 0,05 dengan kriteria uji yaitu $\mathrm{H}_{0}$ ditolak dan $\mathrm{H}_{1}$ diterima, jika perolehan nilai sig. $<0,05$. Berikut adalah hasil dari pengujian uji $\mathrm{T}$ dua sampel independen dapat dilihat pada tabel di bawah ini:

Tabel 1.Hasil Uji Hipotesis

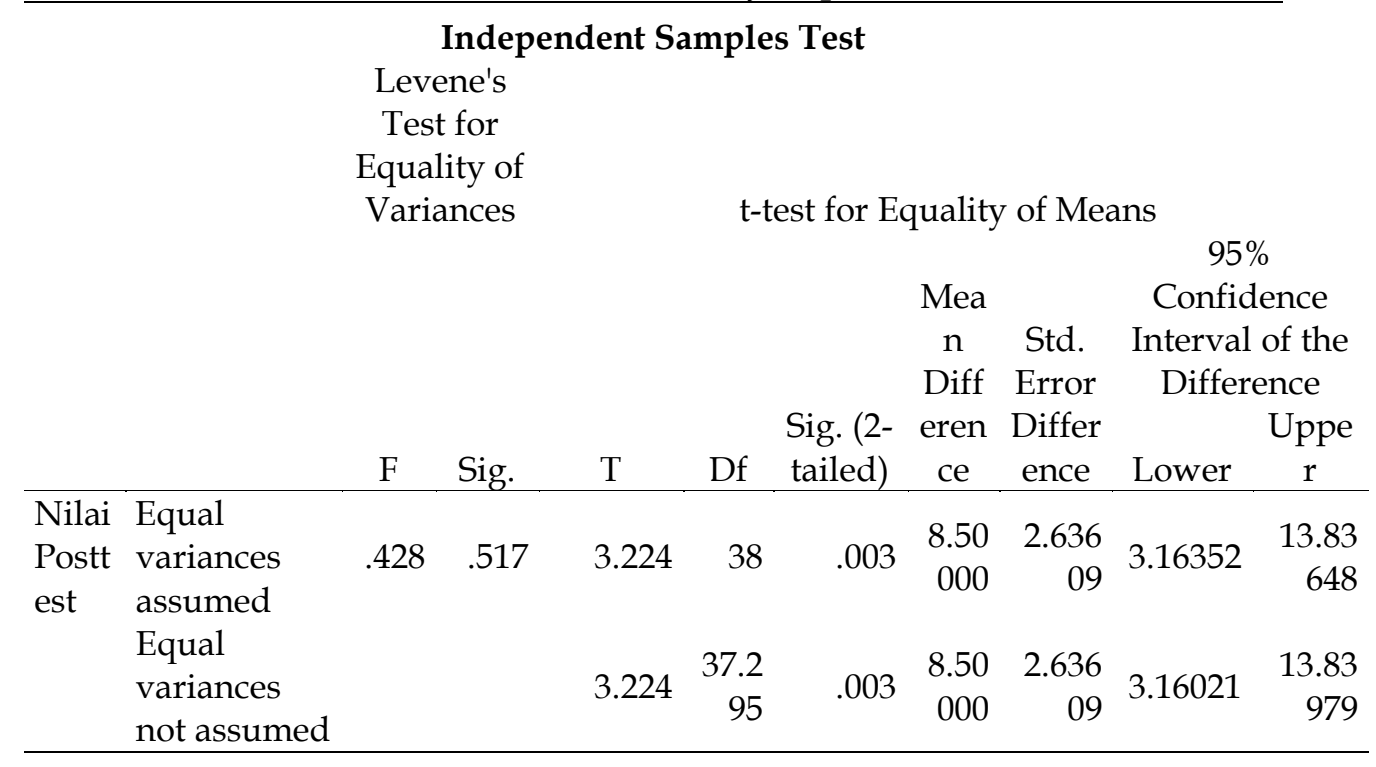

Pengujian hipotesis menggunakan uji Independent Sample T-Test diperoleh nilai Sig. (2tailed) 0,003 karena nilai sig. < 0,05 maka dapat disimpulkan bahwa $\mathrm{H}_{0}$ ditolak dan $\mathrm{H}_{1}$ diterima. Artinya, terdapat perbedaan hasil yang signifikan antara kelas eksperimen dan kelas kontrol.

Berdasarkan hasil analisis dari perolehan nilai tes keterampilan menulis karangan argumentasi siswa kelas eksperimen lebih baik dibandingkan dengan siswa kelas kontrol. Secara umum adanya perbedaan tersebut karena pada proses pembelajaran di kelas eksperimen menggunakan lagu wayang sukuraga yang berjudul mata dan telinga. Berdasarkan hasil data analisis pretest dan posttest yang telah diberikan pada kelas ekperimen dan kelas kontrol diperoleh hasil bahwa siswa yang belajar dengan menggunakan lagu wayang sukuraga mengalami peningkatan dan memiliki rata-rata nilai yang lebih tinggi dibandingkan dengan siswa yang belajar tanpa menggunakan lagu wayang sukuraga. 
Adapun indikator keterampilan menulis siswa sudah sesuai dengan indikator karangan argumentasi menurut (Zakariya, 2020: 22) yakni dari segi kelengkapan argumen dengan argumen-argumen yang disertai fakta, bukti, serta contoh yang dapat mempengaruhi pembacanya sehingga mereka dapat menerima pendapat tersebut. Dari organisasi isi yaitu mencakup tiga hal pokok yaitu pendahuluan, isi, dan penutup. Dari kesesuaian isi dengan judul yaitu menuliskan judul menarik sesuai dengan topik yang diargumentasikan dan terfokus pada teks. Serta dari kosakata, tata bahasa dan ejaan sesuai EBI. Keberhasilan siswa dalam belajar tidak terlepas dari peran guru dengan upaya menerapkan media yang dapat membuat suasana pembelajaran yang nyaman dan menyenangkan sehingga siswa dapat mengembangkan kreatifitas siwa dalam pembelajaran. Hal tersebut sesuai dengan pendapat Kibtiyah dan Abbas (2014: 62) bahwa pembelajaran yang disajikan melalui lagu dapat menstimulus siswa untuk memberikan argumentasi dengan pengenalan kosakata baru dan penguatan tata bahasa yang dikemas secara menyenangkan dengan nuansa yang baru sehingga memotivasi siswa untuk lebih semangat dalam belajar.

Hasil penelitian tersebut sesuai dengan penelitian yang dilaksanakan (Juwita \& Nasution, 2018: 6) menyatakan bahwa penerapan media lagu dalam pembelajaran menunjukkan pengaruh positif yang signifikan terhadap kemampuan menulis karangan argumentasi siswa SDIT Ash Sholihin pada tahun pelajaran 2017/2018. Penelitian lain yang dilaksanakan (Tristanto \& Sutikno, 2018: 78) penelitian ini menunjukkan hasil belajar siswa telah mencapai ketuntasan belajar klasikal, artinya hasil belajar menggunakan media lagu lebih efektif dalam pembelajaran. Berdasarkan beberapa penelitian di atas, media lagu berpengaruh terhadap keterampilan menulis siswa.

Hasil penelitian ini terbatas pada penerapan lagu wayang sukuraga dalam keterampilan menulis karangan argumentasi siswa yang diterapkan pada kelas V SDN Baros Kencana CBM. Adapun faktor-faktor lain yang mungkin mempengaruhi meningkatnya nilai tersebut seperti motivasi belajar, sikap, bakat, minat, faktor intelegensi dan emosional siswa dalam menangkap materi pembelajaran yang tidak dibahas dalam penelitian ini, dikarenakan fokus peneliti hanya sebatas pada penggunaan lagu wayang sukuraga berjudul mata dan telinga. Dengan demikian, dalam penelitian selanjutnya peneliti mengharapkan untuk membahas faktor lain yang mungkin dapat mempengaruhi keterampilan menulis karangan argumentasi.

\section{Kesimpulan}

Berdasarkan hasil penelitian, dapat disimpulkan bahwa lagu wayang sukuraga berpengaruh terhadap hasil belajar keterampilan menulis karangan argumentasi siswa kelas V SDN Baros Kencana CBM. Artinya terdapat perbedaan yang signifikan antara kelas eksperimen dan kelas kontrol. Namun, penelitian ini dibatasi pada penggunaan lagu wayang sukuraga pada mata pelajaran bahasa Indonesia di kelas V SDN Baros Kencana CBM. Dengan demikian perlu dilakukan penelitian lanjutan untuk mengetahui pengaruh variabel yang sama terhadap subjek dan kompetensi yang berbeda agar dapat memperluas ilmu pengetahuan dan mencapai tujuan pembelajaran. 


\section{Daftar Pustaka}

Anggraeni, S. W. (2016). Penggunaan Media Lagu Anak Dalam Meningkatkan Hasil Pembelajaran Menulis Puisi. Jurnal Sekolah Dasar, 1(1), 49-60.

Azhari, S. N., Cahyani, I., \& Kirana, P. (2019). Application Model Cooperative Integrated Reading and Composition (CIRC) to Improve Reading Comprehension Skills of Class V Elementary School Student. International Journal of Science and Applied Science: Conference Series, 3(1), 150.

Dewi, R. dan Yuliana E. (2018). Strategi Pembelajaran Menulis Paragraf Argumentasi Berbasis Saitifik Pada Peserta Didik SDN Sungai Pinyuh. Jurnal Bahasa dan Sastra Indonesia. 1(2), 188-200.

Febriyanto, B. \& Yanto, A. (2019). The Effectiveness of Photo Story in Multiliteracies Learning towards Narrative Writing Skills of Fifth Grade of Elemantary School Students. Al Ibtida: Jurnal Pendidikan Guru MI, 6(2), 191-203. http://dx.doi.org/10.24235/al.ibtida.snj. v6i2.4943

Juwita, P. \& Nasution, A. (2019). Pengaruh Media Lagu Terhadap Kemampuan Menulis Karangan Argumentasi Siswa SDIT Ash-Sholihin. Jurnal Bahasa, Sastra Dan Budaya, 6(2), 1-7.

Kibtiyah, A. M. \& Abbas, N. (2014). Peningkatan Keterampilan Menulis Puisi Bebas Melalui Metode Sugesti-Imajinasi Dengan Media Lagu. Joyful Learning Journal, 3(1), 61-65.

Maulidiyah, F., \& Yermiandhoko, Y. (2019). Pengaruh Penggunaan Media Lagu Model terhadap Hasil Belajar Siswa Kelas V Sekolah Dasar. Jurnal PGSD, (7) 2645-2654.

Rahman, A., Atmazaki. \& Abdurahman. (2018). Implementasi Pembelajaran Bahasa Indonesia Berbasis Teks. Jurnal Pendidikan Bahasa Dan Sastra Indonesia, 7(3), 9-16.

Siddik, M. (2016). Dasar-Dasar Menulis dengan Penerapannya. Malang: Tunggal Mandiri Publishing.

Sugiyono. (2018). Metode Penelitian Pendidikan. Bandung: Alfabeta.

Supriyadi. (2018). Keterampilan Dasar Menulis. Gorontalo: Ideas Publishing.

Triana, V. (2017). Keefektifan Media Lagu Pembelajaran terhadap Minat dan Hasil Belajar Mata Pelajaran IPA Kelas V SD Negeri Tembok Luwung 01 Adiwerna Kabupaten Tegal. Joyful Learning Journal, 2(2) 1-7.

Tristanto, \& Sutikno, P. Y. (2018). Pengaruh Media Lagu Terhadap Keterampilan Menulis Puisi Bebas Kelas V. Unnes.Ac.Id, 7(3), 29-38.

Wulan, N. S. (2014). Perkembangan Mutakhir Pendidikan Bahasa Indonesia Kurikulum 2013 Sekolah Dasar. Mimbar Sekolah Dasar, 1(2), 177-184.

Zakariya, A. (2020). Pengaruh Model Pembelajaran Think Talk Write dalam Meningkatkan Kemampuan Menulis Karangan Argumentasi Siswa Kelas IV MI Kenongomulyo Magetan Tahun Pelajaran 2019/2020. Skripsi pada Fakultas Tarbiyah dan Ilmu Keguruan IAIN Ponorogo: Diterbitkan. 